\title{
30-days mortality in patients with perforated peptic ulcer: A national audit
}

\author{
Anne Nakano ${ }^{1,4}$ \\ Jørgen Bendix ${ }^{2}$ \\ Sven Adamsen ${ }^{3}$ \\ Daniel Buck ${ }^{4}$ \\ Jan Mainz \\ Paul Bartels' \\ Bente Nørgård ${ }^{4,6}$ \\ 'The Danish National Indicator \\ Project, Regionshuset Aarhus, \\ Aarhus, Denmark; ${ }^{2}$ Department \\ of Gastrointestinal Surgery \\ L, Aarhus University Hospital, \\ Denmark; ${ }^{3}$ Digestive Disease \\ Center, Section for Gastrointestinal \\ Surgery, Copenhagen, Denmark; \\ University Hospital Herlev, Denmark; \\ ${ }^{4}$ Department of Clinical Epidemiology, \\ Aarhus University Hospital, Aarhus, \\ Denmark; ${ }^{5}$ Department of Psychiatry \\ Region North, Denmark and Institute \\ of Public Health, University of Southern \\ Denmark, Odense, Denmark; ${ }^{6}$ Center \\ for National Clinical Databases, South, \\ Odense University Hospital, and \\ Epidemiology, Institute of Public Health, \\ University of Southern Denmark, \\ Odense, Denmark
}

Correspondence: Anne Nakano Regionshuset Aarhus, Olof Palmes Allé 15, 8200 Aarhus N, Denmark Tel +4587284976 Fax +4587284983 Email anne.nakano@stab.rm.dk
Background: In 2005, The Danish National Indicator Project (DNIP) reported findings on patients hospitalized with perforated ulcer. The indicator "30-days mortality" showed major discrepancy between the observed mortality of $28 \%$ and the chosen standard (10\%).

Rationale: An audit committee was appointed to examine quality problems linked to the high mortality. The purpose was to (i) examine patient characteristics, (ii) evaluate the appropriateness of the standard, and (iii) audit all cases of deaths within 30 days after surgery.

Methods: Four hundred and twelve consecutive patients were included and used for the analyses of patient characteristics. The evaluation of the standard was based on a literature review, and a structured audit was performed according to the 115 deaths that occurred.

Results: The mean age was 69.1 years, $42.0 \%$ had one co-morbid disease and $17.7 \%$ had two co-morbid diseases. 45.9\% had an American Association of Anaesthetists score of 3-4. We found no results on mortality in studies similar to ours. The audit process indicated that the postoperative observation of patients was insufficient.

Discussion: As a result of this study, the standard for mortality was increased to $20 \%$, and the new indicators for postoperative monitoring were developed. The DNIP continues to evaluate if these initiatives will improve the results on mortality.

Keywords: mortality, perforated peptic ulcer, ulcer, audit

\section{Background}

In January 2005, The Danish National Indicator Project (DNIP) reported its first findings in patients hospitalized in public hospitals with perforated peptic ulcer. ${ }^{1-3}$ The results showed that the quality of hospital treatment was satisfactory for most of the chosen process indicators, but for the outcome indicator "30-days mortality in patients with perforated peptic ulcer" there was a major discrepancy between the observed national mortality of 28\% (115 of 412 patients) and the a priori chosen threshold value (standard) of 10\%. No single hospital or region in Denmark differed significantly from the observed national findings of the 30-days mortality, which indicates a general national problem. The findings caused concern and attention in the Danish health care system, politically, and in the media.

The Danish National Indicator Group for emergency surgery comprises national specialists of surgical gastroenterology, anesthesiologists, and a specialist in clinical epidemiology appointed by their scientific societies. The group found it of utmost importance to audit the results regarding mortality in order to assess possible explanations for the high mortality. Furthermore, the group speculated whether the standard of $10 \%$ was too low according to the characteristics of Danish patients, or the mortality actually was unacceptably high.

\section{Rationale}

This study (i) examined characteristics for Danish patients, reported to the DNIP, with perforated peptic ulcer, (ii) evaluated the appropriateness of the standard based on an 
updated literature review and the results of characteristics of Danish patient, and (iii) audited all cases of deaths occurring within 30 days after surgery for perforated ulcer in order to identify possible causative factors and quality problems.

\section{Methods}

\section{Study population}

With data from the DNIP, 412 consecutive unselected patients were included from February 1, 2003 to August 31,2004 . All had undergone surgery for perforated peptic ulcer, and all 412 patients were selected for the analyses of patient characteristics. When we audited those who died within 30 days after surgery for perforated ulcer, we selected 115 cases of deaths among the 412 patients.

The completeness of reporting patients to the DNIP has been estimated nationally by record linkage to a central administrative register (the Danish National Registry of Patients), which is used routinely to monitor hospital admissions, waiting lists, and certain treatments in the public and private health care sectors. This registry includes the unique civil registration number (given to all Danish citizens at birth), dates of hospital admission and discharge, procedures performed, and up to 20 discharge diagnoses coded by physicians at discharge according to the International Classification of Diseases. By linkage of the civil registration number between the Danish National Registry of Patients and the DNIP we found that approximately 53\% of all Danish patients with perforated ulcer were registered in the DNIP database in the period September 1, 2004-August $31,2005$.

\section{Characteristics of patients with perforated peptic ulcer and information on death}

The DNIP on patients with perforated ulcer includes information on demographic data and a wide range of clinical details. Patient characteristics were thus given according to gender, age, the American Association of Anaesthetists (ASA) score, co-morbid diseases (diabetes, chronic obstructive lung disease, heart disease, liver cirrhosis, malignancy, AIDS), duration of symptoms before hospital admission, whether surgery was performed within six hours after anesthesiological evaluation, and data on circulatory instability at the time of admission.

Information regarding death was collected from the nationwide Civil Registration Number System, which provides every Danish citizen with a civil registration number and contains information on date of birth, gender, all changes of address, civil status, date of emigration, and date of death on every Danish citizen.

\section{Assessment of the threshold value (standard) for 30-days mortality}

When the DNIP was initiated, the Danish National Indicator Group estimated the 30-days mortality standard to be set at $10 \%$ based on a literature study. A new literature search in 2007 was initiated in order to evaluate the appropriateness of the chosen standard. This re-assessment focused on similarities and discrepancies between international patient populations and Danish patients with perforated peptic ulcer.

\section{The audit process}

A qualitative nationwide audit was carried out including review of medical records of all the 115 deaths that occurred within 30 days after surgery for perforated ulcer. The audit committee comprised (i) six surgeons appointed by The Danish Society of Surgeons, (ii) five anesthesiologists appointed by the Danish Society for Anaesthesiology and Intensive Care Medicine, and (iii) a clinical epidemiologist. Initially, all cases of deaths were reviewed by a chief surgeon. This first review generated specific questions for the audit committee related to the episodes of care of patients with perforated peptic ulcer (Appendix 1). Two sets of questions were then generated: one set for the surgeons in the audit committee (five questions), and one set for the anesthesiologists (seven questions). The anesthesiologists required two questions more than the surgeons to assess the entire patient course. The request was met and all questions were evaluated and adjusted twice before use (Tables 2 and 3).

In December 2004, letters with information about the audit were sent to the head of the departments in all 30 surgical departments in Denmark requesting anonymized copies (regarding names and civil registration numbers) of the medical records for the 115 dead patients; and by May 2005 all patient records had been obtained. The medical records were sent to the members of the audit committee. The auditors then conducted a qualitative audit where surgeons and anesthesiologists reviewed the medical records. The audit committee decided that if one surgeon evaluated a case or action as unsatisfactory, it was stated as so, even if the second auditor evaluated it differently. Cases from the western part of Denmark were audited by physicians from the eastern part of Denmark, and vice versa. 
Each case was evaluated independently by two surgeons and one anesthesiologist.

Cases without important documentation necessary for evaluation were not included in the audit process. The number of cases available for evaluation was between 71 and 115 depending on the type of question (the most frequently missing information was anesthesiological documentation for the pre- and intraoperative phase).

\section{Results}

Of the 412 patients who underwent emergency surgery for perforated peptic ulcer, 115 deaths (28\%) occurred within 30 days after surgery. In seven cases $(2 \%)$ valid information on death within the 30 day period could not be obtained because of an invalid civil registration number (due to foreign citizenship) and/or missing data on the date of surgery.

\section{Patient characteristics}

Patient characteristics are shown in Table 1 for all 412 patients presented overall, and according to death or not within 30 days after surgery. Overall, the mean age was 69.1 years. At the time of hospitalization 49.5\% (204/412) had an ASA score of $1-2,45.9 \%(189 / 412)$ an ASA score of $3-4$, and $1.9 \%$ (8/412) an ASA score of 5. Regarding co-morbidity, 33.5\% (138/412) had no co-morbid diseases, $42.0 \%$ (173/412) had one co-morbid disease, $17.7 \%$ (73/412) had two diseases, and $6.6 \%$ (27/412) had $\geq 3$ co-morbid diseases. The two most common diseases were heart disease (141/412, 34.2\%) and 'other chronic diseases' (ie, other than diabetes, chronic obstructive lung disease, heart disease, malignant disease and AIDS) $(111 / 412,26.9 \%)$. At the time of hospital admission $7.3 \%$ (30/412) were circulatory instable. The duration of symptoms prior to admission was $\leq 6$ hours for $32.3 \%$ (133/412) of the patients, 7-24 hours for 30.8\% (127/412), and $>24$ hours for $25 \%$ (103/412).

Patients who died within 30 days after surgery had a higher mean age than survivors and were more often females (71/115, $62 \%$ ). The patients who died within 30 days more often had (i) two co-morbid diseases $(24.3 \%$ [28/115] versus $15.5 \%$ [45/290]), (ii) $\geq 3$ co-morbid diseases (11.3\% [13/115] versus $4.5 \%$ [13/290]), (iii) an ASA score of 3-4 (69.6\% [80/115] versus $36.9 \%$ [107/290]), (iv) an ASA score of $5(5.2 \%$ [6/115] versus $0.7 \%$ [2/290]), (v) symptom duration of more than 24 hours before hospital admission (32.2\% [37/115] versus 22.8 [66/290]), and (vi) circulatory instability at the time of admission (11.3\% [13/115] versus 5.9\% [17/290]). Patients who died within 30 days more seldom had surgery within six hours after anesthesiological evaluation, compared to survivors $(69.6 \%$ [80/115] versus $80.0 \%$ [232/290]).

\section{Assessment of the standard of 30-days mortality}

The literature search did not identify studies with data from nationwide databases on patients with perforated peptic ulcer. Our search concentrated on articles in English, and the following search terms were used: Mortality, in-hospital mortality and 30-days mortality were combined with upper gastroduodenal perforation or gastroduodenal peptic ulcer perforation or acute abdominal surgery or gastroduodenal perforation or saturation or surgery. Some smaller studies on mortality and characteristics of patients with perforated peptic ulcer have been published in the 1980s, but did not include information on ASA score, or details regarding co-morbidity., Furthermore, in most cases in-hospital mortality (and not 30-days mortality) was given. ${ }^{4-9}$ Detailed information on ASA score and co-morbidity was only given by Mäkelä and colleagues $(65 \%$ had ASA score $1-2,35 \%$ had ASA score 3-5, 42\% had no co-morbid diseases, $23 \%$ had one co-morbid disease, and $35 \%$ had $\geq 2$ co-morbid diseases). ${ }^{10}$ In the study by Noguierac and colleagues the 30-days mortality was given $(10 \%)$, based on a population with a mean age of 53.1 years and no details regarding ASA score or co-morbid diseases. ${ }^{11}$

Another study by Robson and colleagues found an in-hospital mortality of $19 \%{ }^{12}$ (in the period from January 1, 2000 to July 31, 2002). The mortality was significantly lower after a re-organisation conducted from general settings to services with emergency subspecialization. The 30-days mortality followed the same pattern, but data are not presented in the study. ${ }^{12}$

\section{Audit process}

The quality of the medical records varied considerably. The hospital departments were asked to submit all relevant documentation in each case, but some surgical or anesthesiological documentation was missing in order to adequately answer all questions (Tables 2 and 3). Since the case records were anonymous, it was impossible to ask for supplementary information after the first request. However, the surgical audit concluded that the overall quality of treatment was satisfactory in $52 \%$ of the patients (Table 2). The general impression of the auditors was that the pre- and intraoperative phases were impeccable, in contrast to the postoperative efforts. Regarding the type of surgery performed it was practically always simple closure with omentopexy (the standard operation technique in Denmark). The auditors noticed that the postoperative monitoring of blood pressure, pulse, 
Table I Characteristics of 412 patients with perforated ulcer given according to survival within 30 days after surgery

\begin{tabular}{|c|c|c|c|c|c|}
\hline & & \multicolumn{4}{|c|}{ Survival status 30 days after surgery } \\
\hline & & All $(n=4 \mid 2)$ & Dead $(n=I \mid 5)$ & Alive $(n=290)$ & $\begin{array}{l}\text { Missing data on } \\
\text { survival }(n=7)\end{array}$ \\
\hline \multirow{2}{*}{$\begin{array}{l}\text { Age at time of hospital admission, } \\
\text { years }\end{array}$} & Mean (median) & $69.1(71.7)$ & $77.2(78.2)$ & $66.5(66.9)$ & $42.1(37.2)$ \\
\hline & Range & 19.5-97.0 & 49.1-97.0 & $23.4-94.4$ & $19.5-94.5$ \\
\hline \multirow[t]{2}{*}{ Gender, n (\%) } & Female & $239(100)$ & $71(29.7)$ & $166(69.5)$ & $2(0.8)$ \\
\hline & Male & $173(100)$ & $44(25.4)$ & I24 (7I.7) & $5(2.9)$ \\
\hline \multirow[t]{4}{*}{ ASA score*, n (\%) } & $\mathrm{I}-2$ & $204(100)$ & $25(12.3)$ & I74 (85.3) & $5(2.5)$ \\
\hline & $3-4$ & $189(100)$ & $80(42.3)$ & $107(56.6)$ & $2(1.1)$ \\
\hline & 5 & $8(100)$ & $6(75.0)$ & $2(25.0)$ & - \\
\hline & Missing & II (100) & $4(36.4)$ & $7(63.6)$ & - \\
\hline \multirow{5}{*}{$\begin{array}{l}\text { Number of co-morbid diseases, } \\
n(\%)\end{array}$} & None & $138(100)$ & $17(12.3)$ & $116(84.1)$ & $5(3.6)$ \\
\hline & I & $173(100)$ & $57(33.0)$ & II5 (66.5) & I (0.6) \\
\hline & 2 & $73(100)$ & $28(38.4)$ & $45(61.6)$ & - \\
\hline & $\geq 3$ & $27(100)$ & $13(48.2)$ & $13(48.2)$ & I (3.7) \\
\hline & Missing & I $(100)$ & - & $I(100)$ & - \\
\hline \multirow{4}{*}{$\begin{array}{l}\text { Symptom duration before hospital } \\
\text { admission, } \mathrm{n}(\%)\end{array}$} & $\leq 6$ hours & $133(100)$ & $26(19.6)$ & $105(79.0)$ & $2(1.5)$ \\
\hline & $7-24$ hours & $127(100)$ & $28(22.1)$ & $95(74.8)$ & $4(3.2)$ \\
\hline & $\geq 25$ hours & $103(100)$ & 37 (35.9) & $66(64.1)$ & - \\
\hline & Missing & $49(100)$ & $24(49.0)$ & $24(49.0)$ & I (2.0) \\
\hline \multirow{3}{*}{$\begin{array}{l}\text { Circulatory instable at time of } \\
\text { hospital admission }{ }^{* *}, \mathrm{n}(\%)\end{array}$} & Yes & $30(100)$ & $13(43.3)$ & $17(56.7)$ & - \\
\hline & No & $374(100)$ & $96(25.7)$ & $27 \mid(72.5)$ & $7(1.9)$ \\
\hline & Missing & $8(100)$ & $6(75.0)$ & $2(25.0)$ & - \\
\hline \multirow[t]{3}{*}{ Surgery within 6 hours ${ }^{* * * *}, \mathrm{n}(\%)$} & Yes & $317(100)$ & $80(25.2)$ & $232(73.2)$ & $5(1.6)$ \\
\hline & No & $23(100)$ & $8(34.8)$ & $15(65.2)$ & - \\
\hline & $\begin{array}{l}\text { Time difference could } \\
\text { not be computed }\end{array}$ & $72(100)$ & $27(37.5)$ & $43(59.7)$ & $2(2.8)$ \\
\hline
\end{tabular}

Notes: "ASA score: score I, a completely healthy patient; score 2, a patient with mild systemic disease; score 3, a patient with severe systematic disease that is not incapacitating; score 4, a patient with incapacitating disease that is a constant threat to life; and score 5, a moribund patient who is not expected to live 24 hours with or without surgery; Bhlood pressure $\leq 100 \mathrm{~mm} \mathrm{Hg}$ and heart rate $\geq 100 / \mathrm{min}$; Between time of anesthesiological evaluation and start of surgery.

temperature, respiration/saturation, consciousness, weight, and fluid balance was not well documented in the medical records, and some patients were transferred early from the semi-intensive postoperative ward to the regular ward with a lower observational level.

The anesthesiological audit concluded that the overall quality of treatment was satisfactory in $82 \%$ of the cases (Table 3).

The review process also indicated that especially elderly patients experienced a diagnostic delay, most often because of vague symptoms, an uncharacteristic history, and/or lack of typical signs of peritonitis. Furthermore, the auditors noted that the anesthesiologist and the surgeon sometimes decided intra-operatively that the postoperative level of care in old and frail patients should not take place at an intensive care unit (in 12 of the 115 fatal cases [10\%]).

\section{Discussion}

This study showed that Danish patients, reported to the DNIP with perforated peptic ulcer, had a high mean age of 69 years, an extended symptom duration before hospitalization ( $\geq 6$ hours for $56 \%$ of the patients), two or more co-morbid diseases (one fourth of the patients), and an ASA score of 3-5 in almost $50 \%$ of the cases - indicating severe underlying co-morbid diseases and acute illness. Among the patients who died within 30 days postoperatively, the mean age was even higher (mean 77.2 years), and $75 \%$ had an ASA score of 3-5. The new review of the literature showed that 30-days 
Table 2 Audit results from the surgeons

\begin{tabular}{llll}
\hline $\begin{array}{l}\text { Question } \\
\text { Cases possible to evaluate }\end{array}$ & $\begin{array}{l}\text { Number of satisfying patient } \\
\text { courses, as evaluated by } \\
\text { two surgeons (\% of patient } \\
\text { courses possible to evaluate) }\end{array}$ & $\begin{array}{l}\text { Number of unsatisfying patient } \\
\text { courses, as evaluated by at least } \\
\text { one surgeon (\% of patient courses } \\
\text { possible to evaluate) }\end{array}$ \\
\hline $\begin{array}{l}\text { What was the indication for } \\
\text { the operation }\end{array}$ & 112 & $106(95 \%)$ & $6(5 \%)$ \\
$\begin{array}{l}\text { How was the preoperative } \\
\text { phase handled }\end{array}$ & 112 & $95(85 \%)$ & $17(15 \%)$ \\
$\begin{array}{l}\text { How was the operative } \\
\text { phase handled }\end{array}$ & 114 & $108(95 \%)$ & $6(5 \%)$ \\
$\begin{array}{l}\text { How was the postoperative } \\
\text { phase handled } \\
\begin{array}{l}\text { Complete evaluation of the } \\
\text { course }\end{array}\end{array}$ & 115 & $67(58 \%)$ & $48(42 \%)$ \\
\hline
\end{tabular}

mortality had not earlier been estimated in nationwide data on patients with perforated ulcer. Furthermore, the majority of earlier studies did not include information on ASA score and co-morbidity. Thus, no earlier studies gave valid indications regarding the appropriate level of the standard of 30-days mortality.

The results from the audit process indicated that the postoperative effort and monitoring of patients was not always satisfactory. Generally, there was a lack of routine procedures regarding recording of saturation, blood pressure, pulse, temperature, and fluid balance in the postoperative phase.
A discrepancy is shown between the surgical and anesthesiological answers of the postoperative care (42\% not satisfactory versus $15 \%$, respectively). The assessments were based on the same documents for both surgeons and anesthesiologists. One of the explanations for the discrepancy might be caused by the fact that it was possible for the surgeons to evaluate a larger number of the documents.

Decrease in saturation or low saturation in patients during and after intra-abdominal surgery is related to postoperative complications in high risk patients. ${ }^{13}$ Presently, there is no available evidence for an association between postoperative basic monitoring and mortality. In the future, however, it

Table 3 Audit results from the anesthesiologists

\begin{tabular}{llll}
\hline Question & Cases possible to evaluate & $\begin{array}{l}\text { Number of satisfying patient } \\
\text { courses, as evaluated from } \\
\text { an anesthesiologist's point } \\
\text { of view (\% of patient courses } \\
\text { possible to evaluate) }\end{array}$ & $\begin{array}{l}\text { Number of unsatisfying } \\
\text { patient courses, as evaluated } \\
\text { from an anesthesiologist's } \\
\text { point of view (\% of patient } \\
\text { courses possible to evaluate) }\end{array}$ \\
\hline $\begin{array}{l}\text { How was the anesthesiology course in } \\
\text { general } \\
\text { How was the monitoring of this } \\
\text { patient? (Should the patient have been } \\
\text { monitored at the intensive care unit?) }\end{array}$ & 105 & $98(93 \%)$ & $7(7 \%)$ \\
$\begin{array}{l}\text { How was the preoperative phase } \\
\text { handled? }\end{array}$ & 94 & $73(78 \%)$ & $21(22 \%)$ \\
$\begin{array}{l}\text { How was the intraoperative phase } \\
\text { handled? }\end{array}$ & 71 & $82(85 \%)$ & $14(15 \%)$ \\
$\begin{array}{l}\text { How was the postoperative phase } \\
\text { handled? }\end{array}$ & 103 & $66(93 \%)$ & $5(7 \%)$ \\
$\begin{array}{l}\text { How was the postoperative surveillance } \\
\text { and treatment level handled? }\end{array}$ & 107 & $88(85 \%)$ & $15(15 \%)$ \\
\begin{tabular}{l} 
Complete evaluation of the course \\
\hline
\end{tabular} & 107 & $88(82 \%)$ & $19(18 \%)$
\end{tabular}


might turn out that measurements of blood pressure, pulse, temperature, consciousness, weight, and fluid balance are important prognostic factors for the survival of patients operated for perforated peptic ulcer.

The validity of the findings depends on accurate evaluation of patient characteristics and careful evaluation of records of all patients dying within 30 days after surgery. Several factors indicate that we consider the study valid. Firstly, it is the largest study to date on patients with perforated peptic ulcer. Secondly, the patient characteristics were based on data from DNIP and include information on unselected patients hospitalized in the whole country regardless of the severity of the disease. This nationwide inclusion of consecutive patients thus reduces the risk of selection bias compared to other studies, which are based on study populations from specialized surgical units. Thirdly, our audit process was carefully planned and carried out with anonymous medical records, use of detailed standardized questionnaires, and medical records reviewed by both surgical gastroenterologists and anesthesiologists.

A limitation of the study is that the reporting to the DNIP is not complete (estimated to 53\%). However, this will not necessarily introduce selection bias in our results as long as both prognostically severe and less severe cases are reported. Unfortunately, it was not always possible to find the data we hoped for; either because documents had not been sent to the audit committee or because information in the medical records was missing.

Based on the new literature review we concluded that characteristics of Danish patients with perforated ulcer were not easily compared to patient populations from other studies. The international studies were based on selective study populations from single centers. Only one study focused on 30-days mortality, ${ }^{11}$ and otherwise the focus of the studies was mainly according to the single impact of different prognostic factors predicting death (eg, age, co-morbidity, ASA-score, preoperative delay, ulcer size, operation methods). ${ }^{4-12}$ Furthermore, it was remarkable that earlier studies did not include data on the level of postoperative observation or data on organ supportive treatment. Due to these circumstances it was very difficult to determine an appropriate standard for mortality in Danish patients, based on the experiences from other countries. The initially set standard of $10 \%$ was chosen in the light of what would be "best for the patients". It was, however, clearly too optimistic to expect results on mortality meeting this standard. As indicated by Lee and colleagues ${ }^{7}$ the standard may approach $10 \%$, but based on a population of patients with a mean age of 52 years (contrary to 69 years in our study), and where only $18 \%$ had co-morbid diseases (contrary to $67 \%$ in our study).

There are no earlier studies on the mortality in patients with perforated ulcer that report the level of postoperative observation or focus on the impact of postoperative care. Furthermore, there are at present no national guidelines in Denmark to support recommendations regarding the level of postoperative observation. The postoperative treatment and monitoring consists of several component parts, and the impact of each component on subsequent mortality has not been clarified. The importance of postoperative monitoring of oxygen saturation has been documented, ${ }^{13-15}$ but it is not yet known whether it influences mortality. Similarly, regulation of the fluid balance is probably of importance, but has not been linked to mortality. Adequate postoperative monitoring and treatment requires experienced health care professionals in an intensive care unit, a "step down" unit or an intermediate (high dependence) unit, and in Denmark, a restricted capacity of intensive care and high dependency units may result in a selection policy where candidate patients are prioritized.

Maintaining the standard of $10 \%$ for 30 -days mortality would obviously have been desirable, but it may have a contra productive effect in the clinical departments in the country. It will be difficult to maintain the staff's motivation to report patients to the DNIP if the standard is unattainable. Based on the findings of patient characteristics and the literature review, the audit committee determined the future standard to be $20 \%$. Furthermore, as a consequence of the audit process, indicating a possible insufficient postoperative monitoring, the indicator group developed new indicators on postoperative observations: blood pressure, pulse, oxygen saturation, temperature, and level of consciousness. The above should all be monitored at least twice a day during the first three postoperative days, together with assessment of weight and fluid balance in the first three postoperative days.

The new standard and the new indicators were implemented from September 1, 2006.

This study confirms that alarming indicator results must be taken seriously. We learned that, based on a thorough description of patient characteristics and a critical literature review, we were able to assess a hopefully more appropriate standard. Furthermore, through a structured national audit process we revealed that tentative causative factors (in this case related to mortality) might be identified. This leads to a need for quality assessment within otherwise unexpected areas of the patient care (in this case the postoperative monitoring). The DNIP continues 
the surveillance of the national performance in patients with perforated ulcer, and time will show whether our initiatives improve the results according to mortality.

\section{Acknowledgments}

We thank the surgical departments, providing information on their cases, for their contribution.

\section{Disclosure}

The authors report no conflicts of interest in this work.

\section{References}

1. Mainz J, Krog BR, Bjørnshave B, Bartels P. Nationwide continuous quality improvement using clinical indicators: the Danish National Indicator Project. Int J Qual Health Care. 2004;16(Suppl 1):i45-50.

2. First Report from the Danish National Indicator Project. Emergency upper gastroduodenal surgery, September 1st 2004 to August 31st 2005. The Danish National Indicator project, Aarhus, December 2005. Cited Oct 10, 2008. Available from: http://www.sundhed.dk/wps/portal/_s.155/1859.

3. Adamsen S. Treatment of bleeding gastroduodenal ulcer. A national audit. GUT. 2005;54(Suppl VII):A219.

4. Boey J, Choi SK, Poon A, Alagaratnam TT. Risk stratification in perforated duodenal ulcers. Ann Surg. 1987;205:22-26.

5. Irvin TT. Mortality and perforated peptic ulcer: a case for risk stratification in elderly patients. Br J Surg. 1989;76:215-218.
6. Hermansson M, Staël von Holstein C, Zilling T. Surgical approach and prognostic factors after peptic ulcer perforation. Eur J Surg. 1999; 165:566-572.

7. Lee FY, Leung KL, Lai BS, Ng SS, Dexter S, Lau WY. Predicting mortality and morbidity of patients operated on for perforated peptic Ulcers. Arch Surg. 2001;136:90-93

8. Tønnesen T, Carlsen E. Ulcus Perforatum. Tidsskr Nor Lageforen. 2001;121:790-792.

9. Kujath P, Schwandner O, Bruch HP. Morbidity and mortality of perforated peptic gastroduodenal ulcer following emergency surgery. Langenbecks Arch Surg. 2002;387:298-302.

10. Mäkela JT, Kiviniemi H, Ohtonen P, Laitinen SO. Factors that predict morbidity and mortality in patients with perforated peptic ulcers. Eur J Surg. 2002;168:446-451.

11. Noguiera C, Silva S, Santos NJ, et al. Perforated peptic ulcer: Main factors of morbidity and mortality. World J Surg. 2003;27:782-787.

12. Robson AJ, Richards JMJ, Ohly N, Nixon SJ, Paterson-Brown S. The effect of surgical subspecialization on outcomes in peptic ulcer disease complicated by perforation and bleeding. World J Surg. 2008;32:1456-1461.

13. The Collaborative Study Group on Peri-operative ScvO2 Monitoring. Multicenter study on peri-postoperative central venous oxygen saturation in high-risk surgical patients. Crit Care. 2006;10:R158.

14. Rosenberg J, Dahl JB, Møller JT. Peroperativ og tidlig postoperativ hypoxæmi [Peroperative and early postoperative hypoxæmia]. Ugeskr Laeger. 1991;153:1262-1264.

15. Rosenberg J, Kehlet H. Sen postoperativ hypoxæmi [Late postoperative hypoxæmia] Ugeskr Laeger. 1991;153:1265-1268. 


\section{Appendix I}

\section{The questions for the surgeons were:}

1. Was the indication for surgical intervention satisfying or not?

2. How was the preoperative phase handled? Was it satisfying or not?

3. How was the intra-operative phase handled? Was it satisfying or not?

4. How was the postoperative phase handled? Was it satisfying or not?

5. Overall evaluation from a surgical point of view. Was the process satisfying or not?

\section{The questions for the anesthesiologists were:}

1. How was the anesthesiological course in general? Was it satisfying or not?

2. How was the perioperative monitoring of the patient (eg, was the patient monitored at the intensive care unit or not)? Was it satisfying or not?

3. How was the preoperative phase handled from an anesthesiological point of view? Was it satisfying or not?

4. How was the intra-operative phase handled from an anesthesiological point of view? Was it satisfying or not?

5. How was the postoperative phase handled from an anesthesiological point of view? Was it satisfying or not?

6. How was the postoperative surveillance and treatment level handled from an anesthesiological point of view? Was it satisfying or not?

7. Overall evaluation from an anesthesiological point of view: Was it satisfying or not?

It was possible to make comments after each question in both questionnaires. 